\title{
Gross Chromosomal Aberrations Are Early Alarms for Malignancy: A Re- Emphasis
}

\author{
Hit Kishore Goswami*
}

Department of Genetics, Bhopal University, 24, Kaushalnagar, P.O. Misrod, Bhopal

\begin{abstract}
A few chromatin dots of variable sizes were encountered in squashes of brain tumour tissues viz. medulloblastoma, ependymoma and tuberculoma along with hyper and hypoploid chromosome counts way back in 1973. Similar chromosomal features were again observed in metaphases of persons exposed to methylisocyanate gas in Bhopal during midnight of 2nd to 3rd December, 1984. Follow-up studies continued during 1984-1999 and comparative assessments on chromosomal damages were attempted by SCE (sister chromatid exchanges) as well as by scoring more than a dozen types of chromosomal aberrations on 678 individuals by C and G-banding and Feulgen's and Aceto-orcein staining procedures on cultured-lymphocytes, details of which, have been published earlier. This short paper reemphasizes the importance of certain chromatin dots (named as Marker dots) which were seen emanating from chromosomes. These marker dots appeared reliable early indicators of neoplastic transformations. During follow-up studies on various malignancies we had recorded presence of these marker dots in almost all of them. This computation of slides involved careful scrutiny of more than 40,000 metaphases from patients of various malignancies, pathological disorders and newly discovered chromosome syndromes (e.g. Crossed Renal Ectopia with pelvic lipomatosis; Hemihypertrophy with melanosis of Ito, etc.). Intriguingly, only selective chromosomes are involved (chromosomes 1, 2, 3, 5, 6, 8, 9, 11, 12, 13, 16, 17 and $Y$ ) in emanating marker dots. Obviously, it appears that the molecular attenuation of chromatin structures movable from chromosomes is related with triggering neoplastic transformations. Specific attention was paid on appearance of "marker dots" which were observed in seemingly normal persons but later, after a gap of 2 to 6 years, some of them exhibited signs of malignancy. Such observations were possible only on those persons who could be re investigated after a gap of 2 or 3 years. Gross chromosomal aberrations such as PCD (premature centromeric divisions) acrocentric associations, hyperploid cells, translocations and deletions with marker dots appear to be precursors to firm installation of chromosomal mutagenesis in cultured lymphocytes. Obviously, search for marker dots and these aberrations in metaphases of person(s) belonging to a cancer-patient family can be of vital importance to warn for early diagnosis and prognostic approach. Marker dots simply "alarm" to inform firm installation of chromosomal mutagenesis which encompasses various chromosomal aberrations. In turn, due to many other intragenic factors, cells are transformed to malignant cells in certain individuals.
\end{abstract}

Keywords: Chromosomal inconstancy and malignancy; Gross chromosomal aberrations; Marker Dots and chromosomal mutagenesis; Chromosomal surveys in populations; Early detection of malignancy

\section{Introduction}

Boveri and Winge [1,2] were among pioneers in proposing the hypothesis that chromosomal variations are directly concerned with cancers. Many papers have been published particularly after the discovery of exact diploid chromosome number $(2 \mathrm{n}=46)$ in man by Tjio and Levan [3]. The advent of various banding techniques on chromosomes led to further extensive and very reliable identification of loci and chromosomal segments being translocated to other chromosomes. The chromosomal aberrations (deletions, duplications, translocations inversions and heteroploidy: aneuploidy and polyploidy) were identified and when in higher frequency were tagged to be associated with neoplastic transformations [4-9]. Some additional aberrations like acrocentric associations sometimes leading to Robertsonian translocations, premature centromeric divisions (PCD) were added by various research workers to be associated with some or the other disease including malignancy. Briefly almost all cancer cells possess cells with variable counts of chromosomes (heteroploid cells; $[10,11]$ Quite interestingly, absolutely essential markers of neoplasia were discovered and searched in both naturally and induced cancers in experimental animals and natural human cancers. These minute structures were named as Double minutes" (DMs), which are dumble shaped small structures $[5,7,12-14]$ and are always present in cancer cells as double dots placed very closely to one another. Almost during the same period, we had discovered marker dots which are single (not dumble shaped) larger chromatin structures measuring 1- 2.5 micron in brain cancers and subsequently in many categories of malignancy and in those persons who developed cancer after few years. In several publications this was emphasized that marker dots could be early warnings for installation of chromosomal mutagenesis [15-19] which decidedly lead to the cancerous cells. Unlike double-minutes the marker dots have been frequently observed as emanating from chromosomes. This paper briefly, also outlines certain other simple aberrant features which can be assessed for being complimentary to cause numerical variations in chromosomes viz. aneuploidy and polyploidy in subsequent mitotic divisions.

\section{Materials and Methods}

Lymphocyte culture studies on 678 persons (Table 1) were conducted during 1984-1998 at the Department of Genetics at Bhopal University (MP) India out of which 605 individuals yielded excellent cultures and offered good stained slides for repeated scores and observations. These included 212 apparently normal individuals, 60 mentally handicapped children and adults, 82 methylisocyanate

${ }^{*}$ Corresponding author: Hit Kishore Goswami, Retired Professor, Department of Genetics, Bhopal University, 24, Kaushalnagar, P.O. Misrod, Bhopal, Tel: 07552807950 E-mail: hitkishoreg@gmail.com; goswamihk@yahoo.com

Received August 18 2017; Accepted October 13, 2017; Published October 18 2017

Citation: Goswami HK (2017) Gross Chromosomal Aberrations Are Early Alarms for Malignancy: A Re-Emphasis. Hereditary Genet 6: 187. doi:10.4172/21611041.1000187

Copyright: $\odot 2017$ Goswami HK. This is an open-access article distributed under the terms of the Creative Commons Attribution License, which permits unrestricted use, distribution, and reproduction in any medium, provided the original author and source are credited. 
gas exposed persons (Union carbide tragedy, Bhopal, mid night $2^{\text {nd }}$ to $3^{\text {rd }}$ Dec 1984), 86 persons with syndromes and diseases, and 165 individuals complaining about fertility and abortions. Standard protocols were followed on cultures using different culture media and staining procedures included simple Giemsa, orcein and Feulgen's techniques; a few slides of each category (Tables 1 and 2) were also processed for $\mathrm{C}$ and $\mathrm{G}$ banding [20-23] Following specific aberrations

\begin{tabular}{|c|c|c|c|c|}
\hline \multirow{3}{*}{$\begin{array}{c}\text { Persons with number of } \\
\text { metaphases } \\
\text { Apparently Normal } \\
(12500 \text { metaphases })\end{array}$} & \multicolumn{4}{|c|}{ Number of times persons investigated } \\
\hline & Once & Twice & Thrice & Total \\
\hline & 170 & 80 & 56 & 306 \\
\hline $\begin{array}{l}\text { Recurrent Abortions } \\
\text { (4544 metaphases) }\end{array}$ & 67 & 140 & 18 & 225 \\
\hline $\begin{array}{c}\text { Syndromes } \\
\text { (4287 metaphase) }\end{array}$ & -- & 09 & 12 & 21 \\
\hline $\begin{array}{c}\text { Malignancies } \\
\text { (1130) metaphses }\end{array}$ & 14 & 05 & 02 & 21 \\
\hline $\begin{array}{c}\text { Methyl isocyanate gas exposed } \\
(11,886 \text { metaphases })\end{array}$ & 14 & 12 & 56 & 82 \\
\hline $\begin{array}{l}\text { Suspected pathology/control of } \\
\text { cancer patients } \\
\text { (1253 metaphases) }\end{array}$ & 08 & 11 & 04 & 23 \\
\hline Totals & 273 & 257 & 148 & 678 \\
\hline
\end{tabular}

Table 1: Persons investigated their category with number of metaphases scored.

\begin{tabular}{|c|c|c|c|c|c|}
\hline \multirow{2}{*}{$\begin{array}{c}\text { Chromo- } \\
\text { some } \\
\text { Number }\end{array}$} & \multirow{2}{*}{$\begin{array}{c}\text { No. of screened } \\
\text { Metaphases }\end{array}$} & \multicolumn{4}{|c|}{ Marker dots emanating from the following } \\
\cline { 3 - 6 } ends & $\begin{array}{c}\text { Near } \\
\text { Centromere }\end{array}$ & $\begin{array}{c}\text { Telomeric } \\
\text { end }\end{array}$ & Arm p & Arm q \\
\hline 1 & 117 & 05 & 51 & 04 & -- \\
\hline 2 & 126 & -- & 117 & - & -- \\
\hline 3 & 125 & -- & 43 & -- & -- \\
\hline 5 & 850 & 03 & 502 & -- & 18 \\
\hline 8 & 180 & -- & 45 & 49 & -- \\
\hline 9 & 120 & -- & 73 & -- & 17 \\
\hline 11 & 165 & ---- & 70 & 12 & -- \\
\hline 12 & 47 & & 29 & -- & -- \\
\hline 13 & 132 & -- & 41 & 18 & 73 \\
\hline 16 & 87 & 10 & 45 & -- & 01 \\
\hline 17 & 140 & -- & 37 & -- & 58 \\
\hline Y & 17 & -- & 12 & - & 27 \\
\hline
\end{tabular}

Table 2: Search for involvement of chromosomes in releasing marker dots.

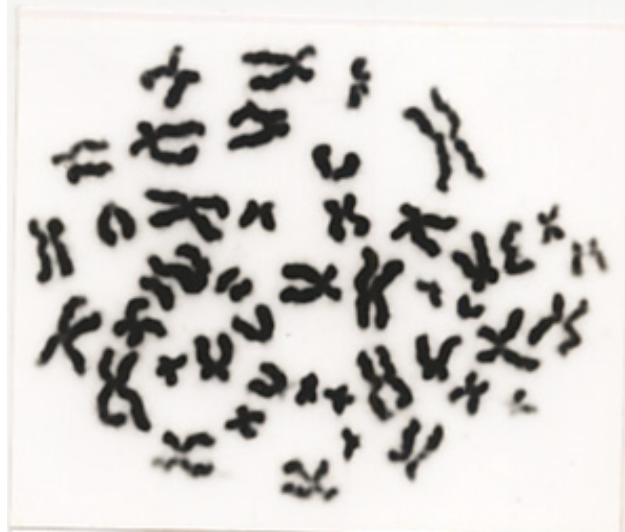

Figure 1: PCD (Premature centromeric division) in a patient of Hemi-hypertrophy with Wilm's tumour. A few chromosomes have shown early longitudinal division of centromere thus separating chromatids earlier than the other chromosomes. This patient showed several metaphases with hypoploid and hyperploids counts of chromosomes (Stained with simple giemsa).

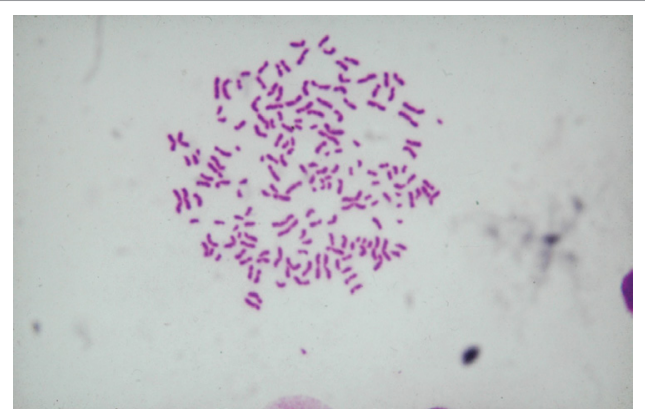

Figure 2: Regular late metaphase, all chromatids separated to move to early anaphase (but checked by colchicines treatment; more than six round marker dots are seen; this female patient later developed (within a year) breast cancer. Lymphocytes were seen with many variable chromosome numbers and several missing chromosomes (Feulge's stain counterstained with $1.5 \%$ acetic porcein).

were scored: Chromosome breaks, Somatic translocations, Acrocentric associations, Marker dots, Premature centromeric divisions, Tandem duplications, Hyperploid cells, Hypoploid cells, Amitotically dividing nuclei and unusual association of chromosomes or chromatids. These details have been mentioned in earlier publications [15,19-24] Blind scoring of slides continued for a long time in search of chromosomal aberrations with alarming attention for "marker dots"; the chromatin dots discovered and observed since 1973 [18]. That these chromatin dots are actually released or expelled chromatin bodies from chromosomes has been repeatedly proved by specific DNA staining procedures (e.g. Feulgen's method; G- as well as C banding) showing marker dots attached (Figure 3 and Table 2) by a fine fibrillar thread [15-19] Table 2 is based on repeated scoring of a large number of slides so as to identify each chromosome involved in releasing the marker dot and frequency of "preferred locus" of each chromosome.

\section{Observations and Comments}

Wherever chromosomal changes take place, there ought to be imposed effects within the cells where they occur; even malignancy is affected by other cells $[25,26]$ as these might become sensitive / prone to mutagenesis. This is not only true for cancer cells but many kinds of chromosomal deviations (structural and or numerical) have been recorded in lower frequencies ( 2 to $4 \%$ ) among seemingly normal persons in the population [15,19,22-24]. Hereunder, only those specific chromosomal aberrations are presented which can be easily detected and their presence in higher frequency (in more than $10 \%$ cells of an individual) offer a definite clue for the installation of chromosomal mutagenesis. As mentioned above many aberrations were scored on all slides which have been published but for this short review only following observations are particularly mentioned in order to reemphasize the population cytogenetic significance of marker dots. Tables 1 and 2 are based on data published earlier as mentioned above.

\section{General aberrations}

Numerical changes in chromosome number: As per our earlier studies 1 to $4 \%$ persons in a population possess (particularly females) heteroploidy (cells with less or more than $2 \mathrm{n}=46$ chromosomes in their lymphocytes). Such aberrant features if present in more than $10 \%$ lymphocytes warn that either the person is a cancer patient (Figures 1 and 2) or will be a cancer patient or will have any such complication which is correlated with malignancy. This becomes imperative to mention here that proportionately, the methylisocyanate exposed persons in Bhopal (Central India) the incidence of cancer patients has increased and all such persons are exhibiting chromosomal aberrations $[27,28]$. 


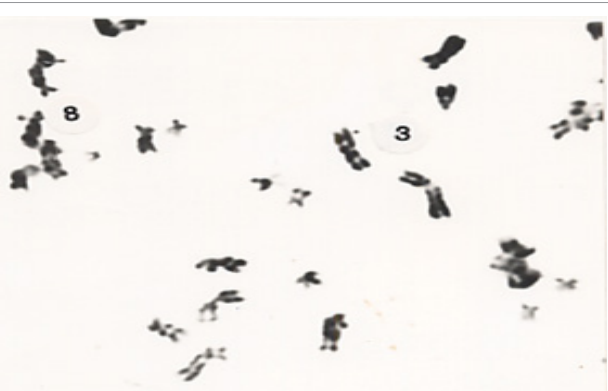

Figure 3: A part of spread metaphase in a lymphocyte from bone cance patient showing marker dots emanating from $\mathrm{Ch} 3$ and $\mathrm{Ch} 8$; several other chromosomes were not showing normal morphology ( $\mathrm{G}$ banded slide).

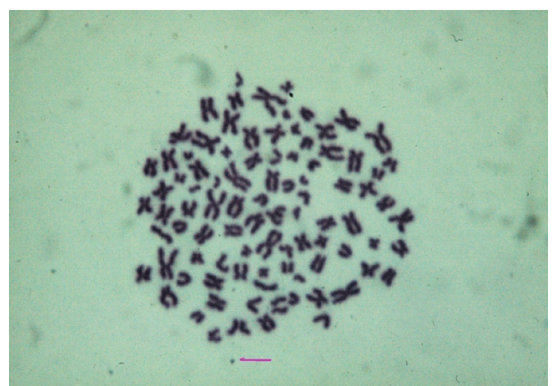

Figure 4: A typical polyploidy in a bone cancer cell with a MD (marker dot arrowed). Certain chromosomes (small acrocentric ones) show early separation of chromatids. (Giemsa stained slide).

Premature centromeric division: This is often ignored by most workers but the untimely longitudinal splitting of centromeres of certain chromosomes (Figures 1 and 2) is one of the causes of numerical variation. Subsequent mitotic divisions will have irregular segregation of chromatids at anaphase and the cells so formed after telophase will have inconstant number, which in turn on replication in Interphase (G1-S phase) will lead to cells with variable chromosome numbers.

Acrocentric associations: There are a large number of publications indicating that acrocentric association of chromosomes sometimes leads to Robertsonian translocations. Even otherwise, acrocentric association normally causes irregular segregation and unequal movements of chromosomes thus making aneuploid cells in subsequent cell cycles. While all chromosomes split longitudinally to facilitate movement of chromatids to different poles acrocentric chromosomes may move to either pole thus causing imbalance in distribution of chromosomes after the cell division $[15,18,21]$.

\section{Specific aberrations}

Marker dots: Marker dots are chromatin structures (up to 2.5 micron) released from either chromatid of a chromosome (Figure 3). We have observed them earlier in brain tumours [29] and later, consistently in cancer patients as well as in persons prone for malignancy. This work is based on vigilant examination of thousands of slides of cultured lymphocytes for chromosome studies and this was recoded that MDs were typically expelled from chromatids of specific chromosomes [19]. Marker dots have been reported in various syndromes and methyl isocyanate exposed persons [15,20-23]. Since MDs are expelled from many chromosomes in many malignancies like breast cancer, colon cancer, Wilm's tumor, bone cancer (Figure 4) and also in some seemingly normal persons from families having cancer incidence among parents and real sibs who may be prone or susceptible for malignancy. But if marker dots can be lifted, micro dissected and cloned and then compared with any moving molecular DNA stretches which are so well affiliated with carcinogenesis [30-33] we may be able to find the exact nature of these moving chromatin bodies.

\section{Discussion}

Chromosomal surveys have been carried out by many laboratories world over not only in the exposed populations by radiations or chemical exposures $[10,15,20]$ in order to monitor and detect some or the other disorders but also with the same objectives in random population samples within accepted protocols [34]. Follow-up studies offer very valuable information on the susceptibility of certain individuals as exemplified by studies in Bhopal of methylisocyanate exposed persons (Exposed in Dec 1984). Increased incidence of recurrent abortions, malignancy reports and other ailments have been computed [20,28,27]. Cells possessing chromosomal variations particularly with variable chromosome numbers (as well as translocations) are often termed as "rouge" cells [35].

It would be a very promising field for "Early Detection of malignancies" if we undertake primary surveys in individuals and their family members by routine chromosome banding techniques. Chromosomes are very sensitive and even if there are molecular changes within the DNA segments (any kind of mutation) which may not be immediately deciphered, there ought to be structural changes. PCD (premature centromeric divisions) acrocentric associations, chromosome laggards, and a few cells with hyperploids chromosome counts (Figure 4). Additionally, MDs (marker dots) must register their presence as signals for warning of chromatin involvements at molecular levels. Having found these structures the investigators with sophisticated molecular cytogenetic techniques can lift these chromatin bodies, clone and compare with moving DNA stretches of retrotransposons and even with many oncogenes. Marker dots are expelled from various chromosomes (Figure 3 and Table 2) variably in different individuals and have always been present in almost all cancer cells as evidenced by my studies over 30 years on 605 individuals. Marker dots are not expelled from all chromosomes (Table 2). We have had carried out repeated studies for three times in more than 100 persons, both normal and with some serious ailment. The presence of marker dots [18] can be shown in more than $50 \%$ slides of a cancer patient anywhere in the world more particularly in patients of breast cancer, colon, and bone and brain cancers. By passing, it may just be mentioned as an hypothesis that release of marker dots may be correlated with the novel chromatin mechanism underlying the progression of tumours with GOF p53, and indirectly suggests new possibilities for designing combinatorial chromatin-based therapies for treating individual cancers driven by prevalent GOF p53 mutations as elegantly opined by Zhu et al. [30] TP53 (which encodes p53 protein) is the most frequently mutated gene among all human cancers. Prevalent p53 missense mutations abrogate its tumour suppressive function and lead to a 'gain-of-function' (GOF) that promotes cancer. Any laboratory with modern molecular cytogenetic approaches may unravel specific molecular mechanism in future. Any laboratory where facilities for modern molecular cytogenetic investigations exist can dip deeper in to the most important problem related to "onset of malignancy".

\section{Conclusion}

Neoplastic transformations of normal cells can be detected by searching for "Rogue" cells (Cells with chromosome aberrations) at an early stage much before the malignant stage becomes clinically detectable. Close relatives and sibs of cancer patients should be chromosomally investigated and each metaphase must be examined to locate marker $\operatorname{dot}(\mathrm{s})$ which are positive indicators of the onset of chromosomal mutagenesis culminating in to malignancy. It would be 
Citation: Goswami HK (2017) Gross Chromosomal Aberrations Are Early Alarms for Malignancy: A Re-Emphasis. Hereditary Genet 6: 187. doi:10.4172/2161-1041.1000187

Page 4 of 4

highly rewarding if someone could lift up and micro-dissect markerdots and clone for comparing with movable assemblage of triggeringoncogenes or similar such DNA sequences.

\section{Acknowledgments}

I will always remain grateful to the late Professor Albert Levan (Lund) and the late Professor T.C Hsu (Houstan) for their initial encouragements and help with references during 1970s. I also express my gratitude to Professor Malcolm Fergusson Smith FRS (Cambridge) who has helped me with enormous literature and learned discussions. My work would not have progressed without the collaborative support of Professor Sung IK Chang, the then Head of the Department of Anatomy and Medical Genetics at Keimyung university Taegu (South Korea) for laboratory facilities and technical help during my several visits as a short term visiting professor. I feel greatly indebted to him and other colleagues Late Dr. I. H. Lee, Professor D K Kim and for technical assistance to Mrs. Son. Needless to mention, I am equally obliged for a very brilliant performance by my colleagues and research scholars at the Department and for clinical assistance and collaborative work of colleagues from hospitals and various departments in Gandh Medical college, Bhopal.

\section{References}

1. Boveri T (1914) Zur Frage der Enstehung maligner Tumoren . Gustav Fischer Jena p. 64.

2. Winge $O$ (1927) Zytologische Untersuchungen uber die Naturmaligner Tumoren I. "Crown gall”der Zuckerrube. Z Zelloforsch Mikroskop Anat 6: 397 (Cited from Levan in 1969).

3. Tjio HJ, Levan A (1956) The chromosome number of man. Hereditas 42: 1-6.

4. Mark $J(1970)$ Chromosome patterns in human meningiomas. European $J$ Cancer 6: 489-498

5. Fleischmann T, Hakansson CH, Levan A, Moller T (1972) Multiple chromosome aberrations in a lymphosarcomatous tumour. Hereditas 70: 243-258.

6. German J (1974) Chromosomes and cancer. Better World Books, New York: John Wiley \& Sons, USA.

7. Levan A (1977) Chromosomes in malignancy. Proceedings of VI International Chromosome conference. Helsinki pp. 339-343.

8. Mitelman F, Levan G (1978) Clustering of aberrations to specific chromosomes in human neoplasms. Incidence and geographic distribution of chromosome aberrations in 856 cases. Hereditas 89: 2-207-232.

9. Therman E, Susman M (1993) Human chromosomes: Structure, behaviour and effects (3rd edn) Springer Verlag, Berlin.

10. Awa AA (1983) Chromosome damage in atomic bomb survivors and their offspring-Hiroshima and Nagasaki. In: Radiation induced chromosome damage in man. T. Ishihara and M.S. Sasaki (Eds.). Alan R. Liss Inc. New York, USA. pp: $235-275$

11. Bonassi S, Norppa H, Ceppil M, Stromberg U, Vermeulen R, et al. (2008) Chromosomal aberration frequency in lymphocytes predicts the risk of cancer: Results from a pooled cohort study of 22,358 subjects in 11 countries. Carcinogenesis 29: 1178-1183.

12. Levan A (1969) Chromosome abnormalities and carcinogenesis; In: Hand book of Molecular Cytology. Edt. Lima de Faria North Holland Printing Co. Amsterdam/London. pp: 717-731.

13. Mark J (1971) Chromosomal aberrations and their relation to malignancy in meningiomas: A meningoma with ring chromosomes Acta Path Microbial Scand 79: 193-200.

14. Mark J, Granberg I (1970) The chromosomal aberrations of double minutes in three gliomas. Acta Neuropath (Berlin) 16: 194-2014.
15. Goswami HK (1986) Cytogenetic effects of methyl isocyanate exposure in Bhopal. Human Genetics (Berlin) 74: 81-84.

16. Goswami HK (1993) Marker dot is indicator of chromosomal mutagenesis. Bionature 13: 325-333.

17. Goswami HK (2006) Levanian translocation: An appraisal. Bionature 26: 87-89.

18. Goswami HK (2016) Cells with chromosomal aberrations trigger neoplastic transformations in humans. Twin Research and Human Genetics 19: 77-79.

19. Goswami HK, Chang SI (2001) Marker dots are expelled by attenuation in heterochromatin of a chromatid. Bionature 21: 41-48.

20. Goswami HK, Chandorkar MS, Bhattacharya K, Vaidyanath G, Parmar D, et al. (1990) Search for Chromosomal variations among gas exposed persons in Bhopal. Human Genetics 84: 172-176.

21. Goswami HK, Rangnekar GV, Varshney S, Gandhi P, Jain B, et al. (1992) Crossed renal ectopia with pelvic lipomatosis: A new Syndrome involving chromosome. Human Genetics 89: 666-670.

22. Goswami HK, Shrivastava N, Gopal SK, Sharma S, Chandorkar MS, et al. (1997) Unusual chromosomal features in a child with gradual disappearance of Right Ulna (Mono-ostolic osteolysis). J Genet Med 1: 11-16.

23. Goswami HK, Rangnekar AG, Sharma S, Varshney S, Lee IH, et al. (1998) Hemihypertrophy with hypomelanosis of Ito: A new syndrome combination. J Genet Med 2: 1-5.

24. Goswami HK (2001) Genetic significance of marker dots. Perspectives in Cytology \& Genetics 10: 265-269.

25. Pathak SN, Mutani MA, Thalmann AS, Von Eschenbach GN (1997) Cancer cells transforms normal host cells into malignant cells? British Journal of Cancer 76: 1134-1138.

26. Hsu TC, Spitz MR, Schnatz SP (1991) Mutagen sensitivity: A biological marker of cancer susceptibility. Cancer Epidemiology Biomarkers and Prevention 1: 83-89.

27. Ganesh N, Sanyal B, Pandey RK, Arti K, Gupta N (2005) Cancer pattern among MIC gas survivors and their offsprings. Health Administrator 19: 50-58.

28. Ghosh BB, Sengupta S, Roy A, Maity S, Ghosh S, et al. (1990) Cytogenetic studies in human populations exposed to gas leak at Bhopal, India. Environ Health Perspectives 86: 323-326.

29. Dharker RS, Chaurasia BD, Goswami HK (1973) Hypoploidy in brain tumours Acta Biologica Academiae Scientiarum Hungaricae 24: 233-235.

30. Zhu J, Sammons MA, Donahue G, Dou Z, Vedadi M, et al. (2015) Gainof-function p53 mutants co-opt chromatin pathways to drive cancer growth. Nature 1: 10.

31. Marco RC, Kramer A (2016) Centrosome amplification, chromosomal instability and cancer: Mechanistic, clinical and therapeutic issues. Chromosome Res 24 105-126.

32. Mirabella AC, Foster BM, Bartke T ( 2016) Chromatin deregulation in disease Chromosoma 125: 75-93.

33. Mita P, Boeke JD (2016) How retrotransposons shape genome regulation. Current Opinion in Genetics \& Development 37: 90-100.

34. Carrano AV, Natarajan AT (1988) International considerations for population monitoring using cytogenetic techniques commission for Protection against environmental mutagens and carcinogens. Mutat Res pp. 379-406.

35. Awa AA, Neel JV (1986) Cytogenetic "rogue" cells: What is their frequency, organic and evolutionary signification? Proc Nati Acad Sci USA 83: 1021-1025 